\title{
Perception of Burden and Stigma by Caretaker of Schizophrenia and Bipolar Disorder: a Comparative Study
}

\author{
Nandaniya KiritKumar L*
}

\begin{abstract}
:
Background burden of care can be conceptualized into two distinct components (objective and subjective). Objective burden of care is meant to indicate its effects on the household such as taking care of daily tasks, whereas subjective burden indicates the extent to which the caregivers perceived the burden of care. Aim of the present study was to assess level of burden and stigma on caretaker of schizophrenia and bipolar patients. Method researcher took $\mathrm{N}=80$ samples from the population of schizophrenia and bipolar disorder. Researcher used ' $t$ ' test, ' $\mathrm{f}$ ' test, correlation test, degree of freedom test to analyzed the data. Results researcher found that caretaker perceived higher stigma and burden, there will be no significant difference in education level. Twenty two $(50.0 \%)$ caretaker of schizophrenia perceived moderate to severe burden comparatively $9(25.0 \%)$ BMD (bipolar manic disorder) perceived moderate to severe burden. Researcher concluded that caretaker of schizophrenia and bipolar both perceived burden and stigma.
\end{abstract}

Keywords: Burden, Stigma, Schizophrenia, Bipolar

\section{INTRODUCTION}

Burden of care can be conceptualized into two distinct components (objective and subjective). Objective burden of care is meant to indicate its effects on the household such as taking care of daily tasks, whereas subjective burden indicates the extent to which the caregivers perceived the burden of care

Severe mental disorders such as schizophrenia and bipolar disorder have far-reaching consequences. Evidence suggests that family members experience significant stress in coping with a person with schizophrenia. The patient's relatives experience feelings of loss and grief. They are confronted with uncertainty and emotions of shame, guilt and anger. Like the patient, they feel stigmatized and socially isolated. Their lives may be disrupted by providing more care than would be normal for someone of the patient's age. In cases where the reciprocity between family members is out of balance, normal care changes to caregiving. Addition of the caregiving role to the already existing family role may become stressful, both psychologically and economically.

* Dept. of Psychology, Sheer S.M. Jadeja Arts \& Com. College, Kutiyana Dist :- Porbandar distribution, and reproduction in any Medium, provided the original work is properly cited. 
Horowitz and Reinhard differentiate between caregiver duties (which encompass the involvement and responsibility of caregivers) and caregiver burden (which they define as the consequence that care giving activities have for families). Treudley referred to burden as the consequence for those in close contact with a severely ill psychiatric patient. The chronic illness of a family member is considered an objective stressor that, because of the care giving tasks, results in a strain for the caregiver or the relative. The consequences for a patient's relatives, formerly referred to as family or care giving burden, have been studied for almost four decades. Initially, the studies were purely descriptive. In the early 1970s, instruments were developed and subsequently used in epidemiological studies and randomized clinical trials. Several researchers have identified factors that adversely influence the experiences of careers-psychological and emotional distress; physical illness; disruption of the family, and social and sexual relationships; curtailment of social activities; and financial hardship. The chronic burden of care giving to a patient with schizophrenia is likely to generate negative emotions and their expression. Expressed emotion (EE) comprises critical or emotionally over-involved attitudes and behaviours. A meta-analysis showed a $48 \%$ median relapse rate in a high EE environment versus $21 \%$ in a low EE environment. Higher subjective levels of burden and personal stress have been reported by high EE relatives compared with low EE relatives. For many carers, frustration, anger, loneliness and despair are common. Levene et al. (1996) reported that the Perceived Family Burden Scale, an instrument for measuring patient behaviour and family burden, demonstrated predictive power for early symptomatic relapse in schizophrenia. It is, therefore, observed that the perceived burden has a serious impact on the caregiver's physical and emotional health; social relationships and perception; and expression of negative emotions such as frustration, despair, loneliness and anger, which have an influence on the course of the schizophrenic illness of the patient under care. There is a dearth of studies assessing the burden of caregivers of patients with schizophrenia and illness-related variables such as age, sex, duration of illness, domicile, marital status, education, employment and previous hospitalization. Therefore, this study was undertaken to find out, using the Burden Assessment Schedule (BAS) by Thara et al., (1998)whether there is any correlation between the perceived burden of caregivers of patients with schizophrenia and age, sex, duration of illness, marital status, previous hospitalization, education, domicile and employment status of the patients.

Stigma is a term originating with ancient, great, denoting a visible mark placed or branded on member of trained group such as trainer or slaves (Guffman, 1963).

Over the last 29 years changes in approach in the field of mental health the emergence of community based methods of treatment and the decrease in economic resources have led to a shift in the responsibility for the care of the ill individual from the institution to the family Having once been identified as the source of the illness blamed and excluded from involvement in care families are now seen as a principal source of support and an important partner in the rehabilitation of the mentally ill. The changes in the mental health system have had a number of important consequences. They have resulted in an increase in the families daily responsibilities 
and sources of stress at a time when they are also dealing with the uncertainty and stigma associated with a chronic psychiatric illness in a close relatives responsibilities.

The negative consequences experienced by family caretakers have been traditionally conceptualized as family burden, which has been commonly conceived as having objective and subjective components. Objective burden includes practical routine limitations on the social, occupational, and familial domains of quality of life, and subjective burden includes such psychological reactions of the relatives as anxiety and depression.

What is schizophrenia?

The schizophrenic disorder is characterized in general by fundamental and characteristic distortion in thinking and perception, and by inappropriate or blunted affect. Clear consciousness and intellectual functioning are usually maintained, although certain cognitive deficits may evolve in the course of time (ICD-10). Markedly aberrant, dysfunctional social behavior has long been recognized to be core characteristics of schizophrenia, Pervasive impairment in social functioning are an integral feature of schizophrenia. The diagnosis of schizophrenia according to DSM-IV-TR requires the presence of no specific symptoms (delusions, hallucination), yet there must be evidence of a clear deterioration in functioning in the area of social relationships, work, and self-care.

Bipolar disorder is a serious mental illness that causes extreme shifts in a person's mood. People with bipolar disorder often have recurring episodes of mania and depression throughout their lives, although many are free of symptoms between these episodes.

\section{METHOD:}

\section{Aim}

The study was conducted to measure the perception of burden and stigma by caregivers of patients with schizophrenia and bipolar disorder.

\section{Objectives}

1. To study of burden on caregivers of schizophrenia.

2. To study of stigma on caregivers of schizophrenia.

3. To study of burden on caregivers of bipolar disorder.

4. To study of stigma on caregivers of schizophrenia.

5. A comparison between caregivers of schizophrenia and caregivers of bipolar disorder.

\section{Hypothesis}

1. There will be significant difference between caregivers of schizophrenia and bipolar disorder. 
Perception of Burden and Stigma by Caretaker of Schizophrenia and Bipolar Disorder: a Comparative Study

2. Caregivers of bipolar perceived more stigma and burden then caregivers of schizophrenia.

\section{Sample}

Overall sampling will be done from government hospital of Gujarat. Total sample sized will be eighty $(\mathrm{N}=80)$.

\section{Inclusion criteria}

1. Taking care of a patient who is 18 years old or above with the diagnosis schizophrenia and bipolar disorder diagnosis research criteria of ICD10-DCR.

2. Primary caregivers.

3. Family history of mental illness.

\section{Exclusion criteria}

1. Uncooperative caregivers

2. If the patient has a diagnosed other than one or more co morbid psychiatric or physical illness.

3. If the caregivers is not living with the patients for at least 12 month.

\section{Tools for assessment}

The following tools have been administered in the study.

1. Clinical data sheet

2. Devaluation consumer scale

3. The zarit burden interview.

\section{RESULT:}

The present study aimed to assess and find stigma and burden among primary caregivers of patient with severe mental illness.

Table.1 Socio-demographic characteristics of Sample

\begin{tabular}{|l|l|l|l|}
\hline \multicolumn{2}{|c|}{ Variables } & N & \% \\
\hline \multirow{4}{*}{ Age } & $18-35$ & 45 & 56.2 \\
\cline { 2 - 4 } & $36-50$ & 31 & 38.8 \\
\cline { 2 - 4 } & 51 above & 4 & 5.0 \\
\hline Sex & Male & 41 & 51.2 \\
\hline
\end{tabular}




\begin{tabular}{|c|c|c|c|}
\hline & Female & 39 & 48.8 \\
\hline \multirow{3}{*}{ Marital status } & Married & 48 & 60.0 \\
\hline & Unmarried & 26 & 32.5 \\
\hline & Separated/divorced/widow & 6 & 7.5 \\
\hline \multirow{2}{*}{ Religion } & Hindu & 56 & 70.0 \\
\hline & Muslim & 24 & 30.0 \\
\hline \multirow{3}{*}{ Occupation } & Employed & 24 & 30.0 \\
\hline & Unemployed & 46 & 57.5 \\
\hline & Others & 10 & 12.5 \\
\hline \multirow{3}{*}{ Family setup } & Ruler & 35 & 43.8 \\
\hline & Urban & 40 & 50.0 \\
\hline & Semi-Urban & 5 & 6.2 \\
\hline \multirow[t]{2}{*}{ SES } & Lower & 38 & 47.5 \\
\hline & Middle & 42 & 52.5 \\
\hline
\end{tabular}

Table.2, Descriptive Statistics of onset of illness and duration of illness.

\begin{tabular}{|l|l|l|l|}
\hline & \multicolumn{1}{|c|}{$\mathrm{N}$} & \multicolumn{1}{|c|}{ Mean } & $\begin{array}{l}\text { Std. } \\
\text { Deviation }\end{array}$ \\
\hline Onset of illness & 80 & 26.25 & 8.74 \\
\hline Duration of illness & 80 & 9.62 & 8.23 \\
\hline
\end{tabular}

Table 3, Distribution of caregivers' responses to statements that measure devaluation of consumers.

\begin{tabular}{|c|c|c|c|c|c|c|c|c|}
\hline \multirow[b]{2}{*}{$\begin{array}{l}\text { Sr. } \\
\text { No. }\end{array}$} & \multirow[b]{2}{*}{ Item } & \multicolumn{4}{|c|}{ Responses } & \multirow[b]{2}{*}{$x^{2}$} & \multirow[b]{2}{*}{ df } & \multirow[b]{2}{*}{\begin{tabular}{|l}
$\mathrm{P}$ \\
value
\end{tabular}} \\
\hline & & $\begin{array}{l}\text { Strongly } \\
\text { agree }\end{array}$ & Agree & disagree & $\begin{array}{l}\text { Strongly } \\
\text { disagree }\end{array}$ & & & \\
\hline \multirow[t]{2}{*}{1} & \multirow{2}{*}{$\begin{array}{l}\text { Accept person as a } \\
\text { close friend. }\end{array}$} & $16(36.4 \%)$ & $18(40.9 \%)$ & $5(11.4 \%)$ & $5(11.4 \%)$ & \multirow[b]{2}{*}{14.17} & \multirow[b]{2}{*}{3} & \multirow[b]{2}{*}{$.003 *$} \\
\hline & & $\begin{array}{l}0 \\
17(47.2 \%)\end{array}$ & $2(5.6 \%)$ & $7(19.4 \%)$ & $10(27.8 \%)$ & & & \\
\hline
\end{tabular}


Perception of Burden and Stigma by Caretaker of Schizophrenia and Bipolar Disorder: a Comparative Study

\begin{tabular}{|c|c|c|c|c|c|c|c|c|}
\hline \multirow[t]{2}{*}{2} & \multirow{2}{*}{$\begin{array}{l}\text { Dangerous and } \\
\text { unpredictable. }\end{array}$} & $13(29.5 \%)$ & $15(34.1 \%)$ & $5(11.4 \%)$ & $11(25.0 \%)$ & \multirow[b]{2}{*}{17.69} & \multirow[b]{2}{*}{3} & \multirow[b]{2}{*}{$.001 * *$} \\
\hline & & $15(41.7 \%)$ & $7(19.4 \%)$ & $14(38.9 \%)$ & $0(.0 \%)$ & & & \\
\hline \multirow[t]{2}{*}{3} & \multirow{2}{*}{$\begin{array}{l}\text { Worse than being } \\
\text { addicted to drugs }\end{array}$} & $22(50.0 \%)$ & $9(20.5 \%)$ & $5(11.4 \%)$ & $8(18.2 \%)$ & \multirow[b]{2}{*}{4.90} & \multirow[b]{2}{*}{3} & \multirow[b]{2}{*}{.179} \\
\hline & & $17(47.2 \%)$ & $2(5.6 \%)$ & $6(16.7 \%)$ & $11(30.6 \%)$ & & & \\
\hline \multirow[t]{2}{*}{4} & \multirow[t]{2}{*}{ Looking down on } & $18(40.9 \%)$ & $11(25.0 \%)$ & $7(15.9 \%)$ & $8((18.2 \%)$ & \multirow[b]{2}{*}{1.87} & \multirow[b]{2}{*}{3} & \multirow[b]{2}{*}{.599} \\
\hline & & $16(44.4 \%)$ & $9(25.0 \%)$ & $8(22.2 \%)$ & $3(8.3 \%)$ & & & \\
\hline \multirow[t]{2}{*}{5} & \multirow{2}{*}{$\begin{array}{l}\text { Regardless of } \\
\text { whether he or she } \\
\text { was qualified for } \\
\text { the job }\end{array}$} & $2(4.5 \%)$ & $11(25.0 \%)$ & $11(25.0 \%)$ & $20(45.5 \%)$ & \multirow[b]{2}{*}{1.27} & \multirow[b]{2}{*}{3} & \multirow[b]{2}{*}{.736} \\
\hline & & $4(11.1 \%)$ & $8(22.2 \%)$ & $8(22.2 \%)$ & $16(44.4 \%)$ & & & \\
\hline \multirow[t]{2}{*}{6} & \multirow[t]{2}{*}{ Thinking less of } & $6(13.6 \%)$ & $21(47.7 \%)$ & $7(15.9 \%)$ & $10(22.7 \%)$ & \multirow[b]{2}{*}{3.69} & \multirow[b]{2}{*}{3} & \multirow[b]{2}{*}{.296} \\
\hline & & $10(27.8 \%)$ & $11(30.6 \%)$ & $5(13.9 \%)$ & $10(27.8 \%)$ & & & \\
\hline \multirow[t]{2}{*}{7} & \multirow{2}{*}{$\begin{array}{l}\text { A sign of personal } \\
\text { failure }\end{array}$} & $13(29.5 \%)$ & $6(13.6 \%)$ & $9(20.5 \%)$ & $16(36.4 \%)$ & \multirow[b]{2}{*}{2.86} & \multirow[b]{2}{*}{3} & \multirow[b]{2}{*}{$.412 * *$} \\
\hline & & $5(13.9 \%)$ & $6(16.7 \%)$ & $10(27.8 \%)$ & $15(41.7 \%)$ & & & \\
\hline \multirow[t]{2}{*}{8} & \multirow{2}{*}{$\begin{array}{l}\text { Women would not } \\
\text { marry a man who } \\
\text { has been treated } \\
\text { for SMI. }\end{array}$} & $16(36.4 \%)$ & $8(18.2 \%)$ & $13(29.5 \%)$ & $7(15.9 \%)$ & \multirow[b]{2}{*}{3.38} & & \\
\hline & & $14(38.9 \%)$ & $4(11.1 \%)$ & $7(19.4 \%)$ & $11(30.6 \%)$ & & 3 & $.335^{*}$ \\
\hline 9 & People not living & $12(27.3 \%)$ & $18(40.9 \%)$ & $4(9.1 \%)$ & $10(22.7 \%)$ & & & \\
\hline & & $2(5.6 \%)$ & $10(27.8 \%)$ & $11(30.6 \%)$ & $13(36.1 \%)$ & 12.41 & 3 & .006 \\
\hline 10 & Responsible and & $16(36.4 \%)$ & $16(36.4 \%)$ & $3(6.8 \%)$ & $9(20.5 \%)$ & & & \\
\hline & $\begin{array}{l}\text { caring as other } \\
\text { parents. }\end{array}$ & $23(72.2 \%)$ & $6(16.7 \%)$ & $4(11.1 \%)$ & $0(.0 \%)$ & 15.42 & 3 & $.001 * *$ \\
\hline 11. & Friendship refusal & $9(20.5 \%)$ & $20(45.5 \%)$ & $5(11.4 \%)$ & $10(22.7 \%)$ & & & \\
\hline & & $13(36.1 \%)$ & $10(27.8 \%)$ & $8(22.2 \%)$ & $5(13.9 \%)$ & 5.67 & 3 & .128 \\
\hline 12 & Decrees visit. & $5(11.4 \%)$ & $24(54.5 \%)$ & $9(20.5 \%)$ & $6(13.6 \%)$ & & & \\
\hline & & $10(27.8 \%)$ & $7(19.4 \%)$ & $13(36.1 \%)$ & $6(16.7 \%)$ & 11.02 & 3 & $.012 * *$ \\
\hline 13 & $\begin{array}{l}\text { People treat } \\
\text { mentally ill patient } \\
\text { in the same way }\end{array}$ & $9(20.5 \%)$ & $13(29.5 \%)$ & $7(15.9 \%)$ & $15(34.1 \%)$ & & & \\
\hline
\end{tabular}




\begin{tabular}{|c|c|c|c|c|c|c|c|c|}
\hline & $\begin{array}{l}\text { they treat other } \\
\text { families. }\end{array}$ & $10(27.8 \%)$ & $5(13.9 \%)$ & $8(22.2 \%)$ & $13(36.1 \%)$ & 3.04 & 3 & .384 \\
\hline \multirow[t]{2}{*}{14} & \multirow{2}{*}{$\begin{array}{l}\text { People do not } \\
\text { blame parents. }\end{array}$} & $11(25.0 \%)$ & $15(34.1 \%)$ & $10(22.7 \%)$ & $8(18.2 \%)$ & \multirow[b]{2}{*}{2.57} & \multirow[b]{2}{*}{3} & \multirow[b]{2}{*}{$.461 * *$} \\
\hline & & $13(36.1 \%)$ & $11(30.6 \%)$ & $4(11.1 \%)$ & $8(22.2)$ & & & \\
\hline \multirow[t]{2}{*}{15} & \multirow{2}{*}{$\begin{array}{l}\text { Community } \\
\text { rejection. }\end{array}$} & $6(13.6 \%)$ & $11(25.0 \%)$ & $7(15.9 \%)$ & $20(45.5 \%)$ & \multirow[b]{2}{*}{3.94} & \multirow[b]{2}{*}{3} & \multirow[b]{2}{*}{.268} \\
\hline & & $7(19.4 \%)$ & $5(13.9 \%)$ & $11(30.6 \%)$ & $13(36.1 \%)$ & & & \\
\hline
\end{tabular}

**. Correlation is significant at the $\mathrm{p}<.01$ level (2-tailed).

*. Correlation is significant at the 0.05 level (2-tailed).

Table.4, Burden among caregivers of patient suffering from schizophrenia and bipolar disorder.

\begin{tabular}{|c|c|c|c|c|c|c|c|}
\hline \multirow[t]{2}{*}{ Diagnosis } & \multicolumn{4}{|c|}{ Burden } & \multirow[b]{2}{*}{$x^{2}$} & \multirow[b]{2}{*}{$\mathrm{df}$} & \multirow{2}{*}{$\begin{array}{c}\mathrm{P} \\
\text { value }\end{array}$} \\
\hline & $\begin{array}{l}\text { No or little } \\
\text { Burden }\end{array}$ & $\begin{array}{l}\text { Milled or } \\
\text { moderate } \\
\text { burden }\end{array}$ & $\begin{array}{l}\text { Moderate to } \\
\text { severe } \\
\text { burden }\end{array}$ & $\begin{array}{l}\text { Severe } \\
\text { burden }\end{array}$ & & & \\
\hline Schizophrenia & $9(20.5 \%)$ & $11(25.0 \%)$ & $22(50.0 \%)$ & $2(4.5 \%)$ & \multirow{2}{*}{6.05} & \multirow{2}{*}{3} & \multirow{2}{*}{$.109 * *$} \\
\hline $\begin{array}{l}\text { BMD(Bipolar } \\
\text { Manic Disorders) }\end{array}$ & $8(22.2 \%)$ & $15(41.7 \%)$ & $9(25.0 \%)$ & $4(11.1)$ & & & \\
\hline
\end{tabular}

**. Correlation is significant at the $\mathrm{p}<.01$ level (2-tailed).

*. Correlation is significant at the 0.05 level (2-tailed).

\section{DISCUSSION}

The table-1 gives descriptive information about the socio-demographic characteristics of the entire sample. In the sample of 80 patient and caregivers $56.2 \%$ were in the age group of 18 35 years. $51.0 \%$ were male. $75.0 \%$ educated $25.0 \%$ uneducated. $30.0 \%$ employed and $57.5 \%$ were unemployed. About $50.0 \%$ patient and caregivers were from urban background and $43.8 \%$ 
were from rural background. $60.0 \%$ were married $32.5 \%$ unmarried, $7.5 \%$ were separated/divorced/widow. $70.0 \%$ were Hindu and $30.0 \%$ Muslim.

Table 2 indicate that mean onset of illness is 26.25 and mean duration of illness is 9.62 standard deviation were 8.74 and 8.23 respectively.

Result of table 3 showing that items and responses of caregivers. Table 3 indicate that 16 (36.4\%) caregivers of schizophrenia strongly agree and $17(47.2 \%)$ caregivers of Bipolar disorder strongly agree with 'Accept person as a close friend'. Eighteen cases (40.9\%) caregivers of schizophrenia agree and 2 (5.6\%) caregivers of Bipolar disorder agree with 'Accept person as a close friend'. Five (11.4\%) caregivers of schizophrenia disagree and 7 (19.4\%) caregivers of Bipolar disorder disagree with 'Accept person as a close friend'. Five (11.4\%) caregivers of schizophrenia strongly disagree and $10(27.8 \%)$ caregivers of Bipolar disorder strongly disagree with 'Accept person as a close friend'. it is significant at $\mathrm{p}<.05$ level.

Thirteen $(29.5 \%)$ caregivers of schizophrenia strongly agree and $15(41.7 \%)$ caregivers of Bipolar disorder strongly agree with 'Dangerous and unpredictable'. Fifteen (34.1\%) caregivers of schizophrenia agree and 7 (19.4\%) caregivers of Bipolar disorder agree with 'Dangerous and unpredictable'. Five (11.4\%) caregivers of schizophrenia disagree and 14 (38.9\%) caregivers of Bipolar disorder disagree with 'Dangerous and unpredictable'. Eleven (25.0\%) caregivers of schizophrenia strongly disagree and $0(0.0 \%)$ caregivers of Bipolar disorder strongly disagree with 'Dangerous and unpredictable' were significant at $\mathrm{p}<.01$ level.

Result of table 3 showing that items and responses of caregivers. Table 3 indicate that 22 (50.0\%) caregivers of schizophrenia strongly agree and $17(47.2 \%)$ caregivers of Bipolar disorder strongly agree with 'Worse than being addicted to drugs'. Nine $(20.5 \%)$ caregivers of schizophrenia agree and $2(5.6 \%)$ caregivers of Bipolar disorder agree with 'Worse than being addicted to drugs'. Five $(11.4 \%)$ caregivers of schizophrenia disagree and $6(16.7 \%)$ caregivers of Bipolar disorder disagree with 'Worse than being addicted to drugs'. Eight (18.2\%) caregivers of schizophrenia strongly disagree and 11 (30.6\%) caregivers of Bipolar disorder strongly disagree with 'Worse than being addicted to drugs' it is not significant at any level

Result of table 3 showing that items and responses of caregivers. Table 3 indicate that 18 (40.9\%) caregivers of schizophrenia strongly agree and $16(44.4 \%)$ caregivers of Bipolar disorder strongly agree with 'Looking down on'. Eleven (25.0\%) caregivers of schizophrenia agree and 9 (25.0\%) caregivers of Bipolar disorder agree with Looking down on. Seven (15.9\%) caregivers of schizophrenia disagree and 8 (22.2\%) caregivers of Bipolar disorder disagree with 'Looking down on'. Eight (18.2\%) caregivers of schizophrenia strongly disagree and $3(8.3 \%)$ caregivers of Bipolar disorder strongly disagree with 'Looking down on'. 'P' value were .599 'Looking down on' it is not significant at any level

Result of table 3 showing that items and responses of caregivers. Table 3 indicate that 2 $(4.5 \%)$ caregivers of schizophrenia strongly agree and $4(11.1 \%)$ caregivers of Bipolar disorder 
strongly agree with 'Regardless of whether he or she was qualified for the job'. Eleven (25.0\%) caregivers of schizophrenia agree and $8(22.2 \%)$ caregivers of Bipolar disorder agree with 'Regardless of whether he or she was qualified for the job'. Eleven $(25.0 \%)$ caregivers of schizophrenia disagree and 8 (22.2\%) caregivers of Bipolar disorder disagree with 'Regardless of whether he or she was qualified for the job'. Twenty $(45.5 \%)$ caregivers of schizophrenia strongly disagree and $16(44.4 \%)$ caregivers of Bipolar disorder strongly disagree with 'Regardless of whether he or she was qualified for the job'. ' $P$ ' value were .736 'Regardless of whether he or she was qualified for the job' it is not significant at any level

Result of table 3 showing that items and responses of caregivers. Table 3 indicate that 6 (13.6\%) caregivers of schizophrenia strongly agree and $10(27.8 \%)$ caregivers of Bipolar disorder strongly agree with 'Thinking less of'. Twenty one (47.7\%) caregivers of schizophrenia agree and $11(30.6 \%)$ caregivers of Bipolar disorder agree with 'Thinking less of'. Seven (15.9\%) caregivers of schizophrenia disagree and 5 (13.9\%) caregivers of Bipolar disorder disagree with 'Thinking less of'. Ten (22.7\%) caregivers of schizophrenia strongly disagree and $10(27.8 \%)$ caregivers of Bipolar disorder strongly disagree with 'Thinking less of'. 'P' value were .296 'Thinking less of' it is not significant at any level

Result of table 3 showing that items and responses of caregivers. Table 3 indicate that 13 (29.5\%) caregivers of schizophrenia strongly agree and $5(13.9 \%)$ caregivers of Bipolar disorder strongly agree with 'A sign of personal failure'. Six (13.6\%) caregivers of schizophrenia agree and $6(16.7 \%)$ caregivers of Bipolar disorder agree with 'A sign of personal failure'. Nine (20.5\%) caregivers of schizophrenia disagree and $10(27.8 \%)$ caregivers of Bipolar disorder disagree with 'A sign of personal failure'. Sixteen (36.4\%) caregivers of schizophrenia strongly disagree and $15(41.7 \%)$ caregivers of Bipolar disorder strongly disagree with 'A sign of personal failure'. 'A sign of personal failure' ' $\mathrm{P}$ ' value were .412 it is significant at $\mathrm{p}<.01$ level.

Result of table 3 showing that items and responses of caregivers. Table 3 indicate that 16 (36.4\%) caregivers of schizophrenia strongly agree and 14 (38.9\%) caregivers of Bipolar disorder strongly agree with 'Women would not marry a man who has been treated for SMI'. Eight (18.2\%) caregivers of schizophrenia agree and 4 (11.1\%) caregivers of Bipolar disorder agree with 'Women would not marry a man who has been treated for SMI'. Thirteen (29.5\%) caregivers of schizophrenia disagree and 7 (19.4\%) caregivers of Bipolar disorder disagree with 'Women would not marry a man who has been treated for SMI'. Seven (15.9\%) caregivers of schizophrenia strongly disagree and $11(30.6 \%)$ caregivers of Bipolar disorder strongly disagree with 'Women would not marry a man who has been treated for SMI'. Item1 'P' value were .335 'Women would not marry a man who has been treated for SMI' were significant at 0.05 level.

Result of table 3 showing that items and responses of caregivers. Table 3 indicate that 12 $(27.3 \%)$ caregivers of schizophrenia strongly agree and $2(5.6 \%)$ caregivers of Bipolar disorder strongly agree with 'People not living with SMI patient '. Eighteen (40.9\%) caregivers of schizophrenia agree and $10(27.8 \%)$ caregivers of Bipolar disorder agree with 'People not living with SMI patient '. Four (9.1\%) caregivers of schizophrenia disagree and $11(30.6 \%)$ caregivers 
of Bipolar disorder disagree with 'People not living with SMI patient '. Ten (22.7\%) caregivers of schizophrenia strongly disagree and 13 (36.1\%) caregivers of Bipolar disorder strongly disagree with 'People not living with SMI patient '. 'P' value were .003 'People not living with SMI patient it's not significant at any level

Result of table 3 showing that items and responses of caregivers. Table 3 indicate that 16 (36.4\%) caregivers of schizophrenia strongly agree and $23(72.2 \%)$ caregivers of Bipolar disorder strongly agree with 'Responsible and caring as other parents'. Sixteen (36.4\%) caregivers of schizophrenia agree and $6(16.7 \%)$ caregivers of Bipolar disorder agree with 'Responsible and caring as other parents'. Three (6.8\%) caregivers of schizophrenia disagree and $4(11.1 \%)$ caregivers of Bipolar disorder disagree with 'Responsible and caring as other parents'. Nine $(20.5 \%)$ caregivers of schizophrenia strongly disagree and $0(0.0 \%)$ caregivers of Bipolar disorder strongly disagree with 'Responsible and caring as other parents'. 'Responsible and caring as other parents' ' $\mathrm{P}$ ' value were .001 'Responsible and caring as other parents' were significant at $\mathrm{p}<.01$ level.

Result of table 3 showing that items and responses of caregivers. Table 3 indicate that 9 (20.5\%) caregivers of schizophrenia strongly agree and $13(36.1 \%)$ caregivers of Bipolar disorder strongly agree with 'Friendship refusal'. Twenty $(45.5 \%)$ caregivers of schizophrenia agree and $10(27.8 \%)$ caregivers of Bipolar disorder agree with 'Friendship refusal'. Five (11.4\%) caregivers of schizophrenia disagree and $8(22.2 \%)$ caregivers of Bipolar disorder disagree with 'Friendship refusal'. Ten $(22.7 \%)$ caregivers of schizophrenia strongly disagree and $5(13.9 \%)$ caregivers of Bipolar disorder strongly disagree with 'Friendship refusal'. 'P' value were .128 'Friendship refusal' it is not significant at any level.

Result of table 3 showing that items and responses of caregivers. Table 3 indicate that 5 (11.4\%) caregivers of schizophrenia strongly agree and $10(27.8 \%)$ caregivers of Bipolar disorder strongly agree with 'Decrees visit'. Twenty four $(54.5 \%)$ caregivers of schizophrenia agree and 7 (19.4\%) caregivers of Bipolar disorder agree with 'Decrees visit'. Nine (20.5\%) caregivers of schizophrenia disagree and 13 (36.1\%) caregivers of Bipolar disorder disagree with 'Decrees visit'. Six (13.6\%) caregivers of schizophrenia strongly disagree and $6(16.7 \%)$ caregivers of Bipolar disorder strongly disagree with 'Decrees visit'. ' $P$ ' value were .012 'Decrees visit' were significant at $\mathrm{p}<.01$ level.

Result of table 3 showing that items and responses of caregivers. Table 3 indicate that 9 (20.5\%) caregivers of schizophrenia strongly agree and $10(27.8 \%)$ caregivers of Bipolar disorder strongly agree with 'People treat mentally ill patient in the same way they treat other families.' Thirteen (29.5\%) caregivers of schizophrenia agree and 5 (13.9\%) caregivers of Bipolar disorder agree with 'People treat mentally ill patient in the same way they treat other families.' Seven (15.9\%) caregivers of schizophrenia disagree and 8 (22.2\%) caregivers of Bipolar disorder disagree with 'People treat mentally ill patient in the same way they treat other families.' Fifteen (34.1\%) caregivers of schizophrenia strongly disagree and $13(36.1 \%)$ caregivers of Bipolar disorder strongly disagree with 'People treat mentally ill patient in the 
same way they treat other families.' 'P' value were .384 'People treat mentally ill patient in the same way they treat other families.' it is not significant at any level.

Result of table 3 showing that items and responses of caregivers. Table 3 indicate that 11 $(25.0 \%)$ caregivers of schizophrenia strongly agree and $13(36.1 \%)$ caregivers of Bipolar disorder strongly agree with 'People do not blame parents'. Fifteen (34.1\%) caregivers of schizophrenia agree and $11(30.6 \%)$ caregivers of Bipolar disorder agree with 'People do not blame parents'. Ten (22.7\%) caregivers of schizophrenia disagree and $4(11.1 \%)$ caregivers of Bipolar disorder disagree with 'People do not blame parents'. Eight (18.2\%) caregivers of schizophrenia strongly disagree and $8(22.2 \%)$ caregivers of Bipolar disorder strongly disagree with 'People do not blame parents'. 'P' value were .461 'People do not blame parents' were significant at $\mathrm{p}<.01$ level.

Result of table 3 showing that items and responses of caregivers. Table 3 indicate that 6 (13.6\%) caregivers of schizophrenia strongly agree and 7 (19.4\%) caregivers of Bipolar disorder strongly agree with 'Community rejection'. Eleven $(25.0 \%)$ caregivers of schizophrenia agree and 5 (13.9\%) caregivers of Bipolar disorder agree with 'Community rejection'. Seven (15.9\%) caregivers of schizophrenia disagree and 11 (30.6\%) caregivers of Bipolar disorder disagree with 'Community rejection'. Twenty (45.5\%) caregivers of schizophrenia strongly disagree and 13 (36.1\%) caregivers of Bipolar disorder strongly disagree with 'Community rejection'. 'P' value were .268 'Community rejection' it is not significant at any level.

Table.4 showing that 9 (20.5) caregivers of schizophrenia perceived no or little burden and $8(22.2 \%)$ BMD (Bipolar Manic Disorders) caregivers perceived no or little burden. Eleven (25.0\%) caregivers of schizophrenia perceived Milled or Moderate Burden and 15 (41.7) BMD (Bipolar Manic Disorders) caregivers perceived Milled or Moderate Burden. Twenty two (50.0\%) caregivers of schizophrenia perceived Moderate to Severe Burden and 9 (25.0) BMD (Bipolar Manic Disorders) perceived Moderate to Severe Burden. Two (4.5\%) caregivers of schizophrenia perceived Severe Burden and 4(11.1\%) BMD (Bipolar Manic Caregivers) perceived Severe Burden. It is significant at $\mathrm{p}<.01$ level.

\section{CONCLUSION}

Researcher concluded that there will be significant differences between caregivers of schizophrenia and caregivers of bipolar disorder. Researcher also concluded that caregivers of schizophrenia perceived more burden and stigma than caregivers of bipolar disorder. 


\section{REFERENCE}

1. Ali, R. M., \& Bhatti, R. S. (1988).Social Support System and Family Burden Due to Chronic Schizophrenia in Rural and Urban Background.Indian Journal of Psychiatry, 30(4): 349-353

2. Cassidy, J. (1999). The Nature of A child's Ties. In Cassidy J, Shaver PR. Handbook of Attachment: Theory, Research and Clinical Applications. New York: Guilford Press. 3-20.

3. WHO International Consortium in Psychiatric Epidemiology (2000). Cross-National comparisons of the prevalence and correlates of mental disorders, bulletin of the World Health Organization,74(4).

4. WHO. (2001). The Undefined and Hidden Burden of Mental Health Problems

5. Ostman, M., \&Djellin, L. (2002).Stigma by Association Psychological Factors in Relatives of people with Mental Illness.The British Journal of Psychiatry, 181:494-498.

6. Briggs, D. (2003).Environmental Pollution and the Global Burden of Disease.British Medical Bulletin,68 (1): 1-24.

7. Kadri, N., Manoudi, F., Berrada, S., \& Moussaoui, D. (2004).Stigma Impact on Moroccan Families of Patients with Schizophrenia.The Canadian Journal of Psychiatry, 49:625-629.

8. Srivastava, S. (2005).Perception of Burden by Caregivers of Patient with Schizophrenia.Indian Journal of Psychiatry, 47(3): 148-152.

9. Hinshaw, S. P. (2005). The stigmatization of mental illness in children and parents: developmental issues, family concerns, and research needs, Journal of Child Psychology and Psychiatry,46(7): 714-734.

10. Nehra, R. et al (2005). Caregiver-coping in bipolar disorder and schizophrenia a reexamination.Soc Psychiatry PsychiatrEpidemiol, 40(4): 329-36

11. Annette, P. U., Carlos, C. (2006). Preventing Disease Through Health Environments: Towards an Estimate of The Environmental Burden of Disease. Quantifying Environmental Health Impacts. World Health Organization.

12. Weiss, M.G., Ramakrishna, J. \&Somma, D. (2006).Health-related stigma: Rethinking concepts and interventions, Psychology Health \& Medicine, 11(3): 277-287

13. Jadhav, S., Littlewood, R., Ryder, A. G., Chakraborty, A., Jain, S., \&Barua, M. (2007). Stigmatization of Severe Mental Illness in India: Against the Simple Industrialization Hypothesis. Indian Psychiatric Society, 49(3): 189-194. 
14. Roice, C., Heider, D. B., Angermeyer, M.C., Azorin, J. M., Brugha, T. S., Kilian, R., Johnson, S., Toumi, M., Kornfeld, A., \&Eurosc Research group (2007).Burden on caregivers of people with schizophrenia: comparison between Germany and Britain. British Journal of psychiatric, 190:333-8.

15. Loganathan, S., \& Murthy, S. R. (2008).Experiences of Stigma and Discrimination Endured by People Suffering from Schizophrenia.Indian Journal of Psychiatry, 50(1): $39-46$.

16. Knol, A. B., Petersen, A. C., Sluijs, J., \&Lebret, E. (2009).Dealing with Uncertainties in Environmental Burden of Disease Assessment.Environmental Health.8:21

17. Talwar, R., Srinivasan, T. N. (2010). Caregivers in Schizophrenia: A Cross Cultural Perspective. Indian Journal of Psychological Medicine, 32(1): 29-33.

18. Shah, A. J., Wadoo, O., Latoo, J. (2010).Psychological Distress in Carers of People with Mental Disorders.British Journal of Medical Practitioners, 3:3.

19. Idstad, M., Ask, H., \&Tambs, K., (2010). Mental disorder and caregivers burden in spouses the Nord-Trondelaghalth study. BMC Public Health, 10:516.

20. Samantha, J., McKenzie., McLaughlin, D.,, Dobson, A. J., \&Byles, J. E. (2010).Urban rural comparison of outcome for informal carers of elderly people in the community a systematic review.Elsevier, 67:139-143.

21. Lgberase, O., Morakinyo, O., Lawani, A. O., James, B. O., \&Omoaregaba, J. O. (2010).Burden of Care among Relatives of Patients with Schizophrenia in Midwestern Nigeria.International Journal of Social Psychiatry, 58(2):131-137. 